readable account, and the absence of critical documentation is to a large extent alleviated by the confidence that the whole is based on prolonged and acute observation followed by cautious, disciplined interpretation.

Separate chapters are devoted to the leopard and cheetah, also based on first-hand study, and to the evolution of the physical and behavioural traits that distinguish the lion so clearly from other members of the cat family. Although the last is highly speculative, one could hardly ask for a better informed speculator, and the analysis of the different strategies of these three species is revealing. Tentative explanations, in terms of selective advantage, are offered for such peculiarities of lion behaviour as the infanticide practiced by new males joining a pride and the apparent absence of sexual competition among the adult males of a pride.

Lions will probably become increasingly confined to parks and reserves. The population in the Serengeti is estimated at around two thousand. In smaller reserves a full understanding of the unusual social organization of the species will be especially valuable in planning their conservation.

GORDON B. CORBET

\title{
Rabies, the Facts, by Colin Kaplan and others. Oxford University Press, $£ 1.95$
}

At a time when rabies is not far from the channel coast of France, and the risk of reintroducing the disease into Britain becomes more real, this book will be essential reading for all those concerned with the importation and management of domestic and non-domestic mammals. It has been written in a style suitable for the informed layman but at the same time provides a lot of detailed scientific fact, much of it from recent research, making it a necessity for veterinary surgeons and zoologists. Each chapter is by a different author who has made a special study of a particular aspect of the rabies problem, and thus the subject is covered in considerable depth: rabies in wildlife, domestic stock and man; its transmission and significance in different areas of the world; the morphology and properties of the virus under laboratory conditions; and efforts to develop and improve methods of protection against the disease. One chapter deals with the ecology of the red fox, Britain's most likely reservoir of rabies. In general the book is scholarly, well-written and highly readable. The concept of using a number of authors for a scientific volume is now accepted as the best method for ensuring that it is up to date in all as pects and factually accurate. But one problem with this is that there is often a lot of overlap between the chapters, and this is the only criticism that I would have of this book. For instance, the chapters by Lloyd and MacDonald contain a lot of common material, and more judicious editing might have been used here. Nevertheless, the book meets an important need and should be compulsory reading for those who still think that our quarantine laws are too stiff.

D. M. JONES

\section{The Red Colobus Monkey, by Thomas T. Struhsaker. University of Chicago Press, $£ 17.08$.}

Among other things, this book is a tribute to the New York Zoological Society's farsighted policy of providing substantial support for field studies. Dr Struhsaker, a research zoologist with the NYZS, has spent the major part of 15 years conducting field research in tropical forest areas (notably in Africa) and has made a particular contribution to the study of primate behaviour and ecology. One of his main studies, lasting almost two years (May 1970-March 1972) was of the red colobus Colobus badius tephrosceles in Kibale forest, Uganda. This monograph, one of several outstanding books in the Wildlife Behavior and Ecology series published by University of Chicago Press, is an extremely valuable addition to the literature on primate field studies. There is satisfying attention to quantitative detail in the wide-ranging picture of the life of red colobus, covering group size and structure, various specific aspects of social behaviour, 
vocalisations and ecology (especially in relation to feeding). The text is followed by 58 tables providing detailed numerical data which will be much appreciated by specialists. His interpretations of the data represent another step towards an overall theory of the relationship between primate behaviour and ecology. It is a major step because of the additional information to be drawn from comparison with the strikingly different blackand-white colobus and because of the availability of data from parallel studies conducted by $\mathrm{Dr} T$. Clutton-Brock in Tanzania.

In a note on the threat posed by timber-felling to the remaining areas of African rainforest Struhsaker reiterates a perceptive suggestion that selected areas could well be set up as reserves supported by considerable tourist revenue.

R.D. MARTIN

Recent Advances in Primatology: Vol. 1 Behaviour; 2 Conservation; 3 Evolution; 4 Medicine; edited by D.J. Chivers et al. Academic Press, $£ 19.20, £ 10.50, £ 14.80$, $£ 7.80$.

Primate Ecology: Studies of Feeding and Ranging Behaviour in Lemurs, Monkeys and Apes, edited by T.H. Clutton-Brock. Academic Press, £28.05.

The editors and Academic Press are to be congratulated for publishing so quickly the collected papers of the 1976 Congress of the International Primatological Society, wellproduced and reasonably priced. The second volume, a book that all those involved in practical conservation should read, has three main sections, covering conservation in the wild, trade and supply of primates, and primate breeding in captivity. All contain papers that deal with broad problems plus some more specific descriptive accounts. In the first section, for example, along with primate conservation in general and a discussion of bioeconomic reasons for conserving rainforests, there are papers on primate conservation in Brazil, Cameroon, Ghana, Guyana, India, Indonesia, Kenya, Malaysia and

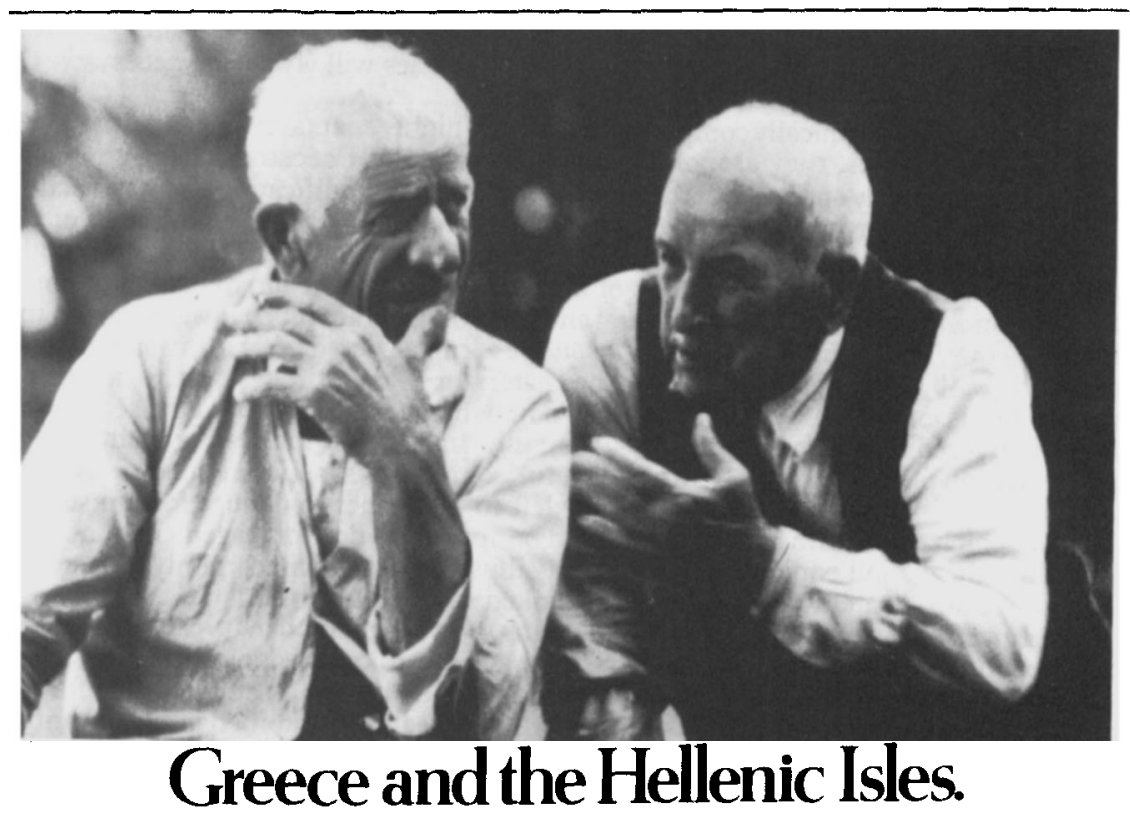

Theyre closer than you think. 